\title{
Clinical aspects of congenital microcephaly syndrome by Zika virus in a rehabilitation center for patients with microcephaly
}

\author{
(iD) Kelson James Almeida ${ }^{\mathbf{1 , 2 , 3}}$ \\ Augusto César Beserra Martins² \\ Isadora Costa Coelho Gayoso e Almendra \\ (iD) Gabriel Medina Sobreira de Meneses ${ }^{4}$ \\ (iD) Thales Daniel de Oliveira Sampaio ${ }^{2}$ \\ (iD) José da Cruz Moura Campêlo \\ (iD) Edson Bor-Seng-Shu ${ }^{3}$
}

1. Centro Integrado de Reabilitação, Teresina, Piauí, Brasil. 2. Faculdade Integral Diferencial, Escola de Medicina - Facid/Wyden, Teresina, Piauí, Brasil. 3. Universidade de São Paulo, Departamento de Neurologia, São Paulo, SP, Brasil. 4. Universidade Federal de Piauí, Teresina, Piauí, Brasil. 5. Centro Universitário Uninovafapi, Teresina, Piauí, Brasil.

\section{SUMMARY}

OBJECTIVE: In this study, we intend to identify the prevalence of clinical variables in children with microcephaly.

METHODS: This is a cross-sectional and observational study with data collected from medical records of patients admitted to the microcephaly outpatient clinic of a referral center in Teresina-PI. Demographic (gender and age) and clinical data (presence of epilepsy, dysphagia, irritability, and associated comorbidities) were collected. The frequency of Zika virus as a probable etiology was determined from computed tomography patterns and the exclusion of other etiologies by serological tests.

RESULTS: A total of 67 patient records were evaluated, of which 31 were male and 36 were female, with a mean age of 1 year and 10 months. The most prevalent clinical variables were epilepsy, present in 47 children (70.2\%), and irritability in 37 (55.2\%). Also with a high frequency, 22 had dysphagia (32.8\%), and 13 had musculoskeletal comorbidities (19.4\%). Only three patients in the sample had cardiac abnormalities (4.5\%), and no endocrine comorbidity was found. A total of 38 children in the sample (56.7\%) presented ZIKV as a probable etiology and, in these cases, there was a higher frequency of epilepsy and dysphagia compared to other etiologies, although not statistically significant.

CONCLUSION: Epilepsy, irritability, dysphagia, and musculoskeletal comorbidities were the most frequent clinical variables in children with microcephaly. There was a high prevalence of congenital ZIKV microcephaly syndrome in this sample.

KEYWORDS: Microcephaly. Zika virus. Epilepsy. Deglutition disorders. 


\section{INTRODUCTION}

Microcephaly is a condition defined as a cephalic perimeter that is more than two standard deviations below the population mean, adjusted for sex and age (z-score <-2); it can be classified as primary (when present at birth) or secondary (when it appears later). When the cephalic perimeter is smaller than three standard deviations, microcephaly is defined as severe. Although the cephalic perimeter itself only measures the size of the skull, it typically reflects brain volume; therefore, abnormal values are important risk factors for intellectual disability, cerebral palsy, epilepsy, and other abnormalities' ${ }^{1}$.

Causes of microcephaly are diverse and include genetic syndromes, chromosomal abnormalities, metabolic disorders, infections, exposure to teratogens, and injuries sustained during prenatal, perinatal, or postnatal care. Despite this, even after imaging, genetic testing, and serological tests, no etiology is often identified ${ }^{2}$. In the years 2015-2016, there was an increase in the frequency of congenital microcephaly in Brasil, especially in the states of the Northeast Region. The association with ZIKV was elucidated by a series of clinical, epidemiological, and experimental evidence ${ }^{3}$.

In the pre-Zika era, the major congenital infections associated with microcephaly were those of the TORCH group: Toxoplasmosis, Other infections (Syphilis, Varicella-Zoster, Parvovirus B-19), Rubella, Cytomegalovirus (CMV) and Herpes virus. Recently, however, Zika virus (ZIKV) infections in pregnant women have been associated with microcephaly and other severe brain abnormalities ${ }^{2}$.

Therefore, the objective of the present study is to clinically characterize a sample of children with microcephaly treated at a referral center in an epidemic area in the context of the outbreak of ZIKV infection.

\section{METHODS}

Retrospectively, the medical records of patients born with a confirmed diagnosis of congenital microcephaly according to a protocol by the Brazilian Ministry of Health ${ }^{4}$ were analyzed. Children aged from 0 to 3 years old were included at the time of data collection, which was performed between October 2017 and January 2018. The sample was obtained from the microcephaly outpatient clinic of the Integrated Rehabilitation Center (CEIR) in Teresina - PI, Brasil. Patients who did not undergo regular medical follow-up (defined as a monthly consultation within the last six months of data collection) were excluded.

From the sample selected, a medical record analysis was performed through a collection form that included demographic (gender and age) and clinical variables, as defined below:

- Epilepsy proven through an interview with a specialist physician and an electroencephalographic report;

- Dysphagia determined through clinical evaluation by speech therapist specialized in swallowing, with evidence of alteration in the oral and/ or pharyngeal phases of swallowing;

- Irritability, crying, and/or restlessness throughout the medical history;

- Cardiovascular comorbidities such as congenital heart disease, patent ductus arteriosus, and atrial septal defect;

- Endocrine disorders such as thyroid disorders, diabetes, and adrenal disorders;

- Musculoskeletal pathologies characterized by muscular weakness, muscular group atrophy, postural alteration, and tendinopathy, mainly in the lower limbs.

The etiology of microcephaly was determined according to computed tomography (CT) patterns, to which the patients were submitted to, and from serological tests and CSF markers, allowing differentiation between the two groups: those with congenital microcephaly syndrome by Zika Virus (ZIKV) as probable etiology and those with non-ZIKV causes of microcephaly. From this categorical classification, the statistical differences in the frequencies of clinical comorbidities were analyzed.

\section{Ethical Aspects}

The information collected had guaranteed confidentiality conferred by the Informed Consent Form signed by the legal responsible, which ensures the privacy and anonymity of the subjects involved in the research. This research was approved by the Local Research Ethics Committee, process number 76823317.7.0000.5211.

\section{Statistical analysis}

The information obtained was used in a statistical analysis in Microsoft Excel and then entered and processed in SPSS (Statistical Package for the Social 
Sciences version 20.0) to generate frequency tables with the purpose of verifying the elements relevant to the research. Fisher's exact test was used to compare the frequency of categorical variables (gender and cause of microcephaly). Significant values of $p$ $<0.01$ were used to establish the significance of the association between variables.

\section{RESULTS}

A total of 67 patient charts were evaluated in the outpatient clinic, of which 31 (46.3\%) were male and $36(53.7 \%)$ female, with a mean age of 1 year and 10 months. Of all microcephaly patients, the diagnosis of ZIKV as a probable etiology occurred in 38 children, corresponding to $56.7 \%$ of all cases of microcephaly. In this group, 14 (36.8\%) of the children were male, and $24(63.2 \%)$ were female, with a mean age of 2 years.

In the total sample of children with microcephaly, the most prevalent clinical variables were epilepsy, present in 47 children (70.2\%), and irritability in 37 (55.2\%). Also, with a high frequency, 22 presented dysphagia (32.8\%), and 13 musculoskeletal comorbidities (19.4\%). Only 3 patients in the sample had cardiac comorbidities (4.5\%), and no endocrine comorbidity was found.

Regarding gender, there was no significant difference between the clinical variables (Table 1). Despite this, the frequency of dysphagia was considerably higher in females. When the gender distribution was specifically assessed in the ZIKV group, this trend was also observed ( $50 \%$ of the children with dysphagia were female and $28.6 \%$ male), although, once again, it was not significant $(p=0.309)$.

The other 29 children who did not have congenital microcephaly syndrome by Zika Virus as a probable etiology were included in a non-Zika group, the vast majority of which were unidentified.

There was no statistically significant difference when comparing the clinical variables for the cause of microcephaly, that is, ZIKV as a probable etiology or the non-Zika group (Table 2). In spite of that, in the sample, the prevalence of epilepsy and dysphagia was much higher in the ZIKV group.

\section{DISCUSSION}

In our study, the high prevalence of musculoskeletal abnormalities, epilepsy, and irritability were noted in both the ZIKV and non-ZIKV groups. Several studies have sought to identify the comorbidities and functional outcomes most frequently associated with microcephaly, both before and after the Zika virus outbreak (pre-Zika study).

An Israeli pre-Zika study conducted with a sample of 1393 children with developmental disorders showed that children with microcephaly of the most diverse causes compared to those with normal head circumference had a higher prevalence of several neurological findings such as hypotonia (31,2\% of children with microcephaly), spasticity (18.6\%), weakness (6.5\%), intellectual disability (38.1\%), cerebral palsy (21.4\%) and epilepsy (28.3\%). Hyperactive behavior was found in about $20 \%$ of all children, with no significant difference between the normocephaly and microcephaly group ${ }^{5}$.

In a large pre-Zika German study that included 680 children with microcephaly, epilepsy was diagnosed in $43 \%$ of patients and intellectual disability in $74 \%$. Abnormalities outside the central nervous system were identified with varying frequencies, including ocular disorders (30\%), cardiovascular disorders (14\%), renal and urinary tract disorders (13\%), skeletal disorders (13\%) and oropharyngeal disorders (13\%). The

TABLE 1. DISTRIBUTION OF CLINICAL COMORBIDITIES BY GENDER IN ALL PATIENTS WITH CONGENITAL MICROCEPHALY ASSESSED FROM RECORDS OF THE INTEGRATED REHABILITATION CENTER, TERESINA (PI).

\begin{tabular}{l|l|l|l}
\multirow{2}{*}{ Clinical Variables } & \multicolumn{2}{l|}{ Gender } & \multirow{2}{*}{$\mathrm{P}$} \\
\cline { 2 - 4 } & Male (31) & Female (36) & \\
\hline Epilepsy & $20(64.5 \%)$ & $27(75 \%)$ & 0.426 \\
\hline Irritability & $18(58.1 \%)$ & $19(52.8 \%)$ & 0.806 \\
\hline Dysphagia & $6(19.4 \%)$ & $16(44.4 \%)$ & 0.038 \\
\hline Musculoskeletal Comorbidities & $5(16.1 \%)$ & $8(22.2 \%)$ & 0.556 \\
\hline Cardiovascular Comorbidities & $2(6.5 \%)$ & $1(2.8 \%)$ & 0.592 \\
\hline Endocrine Comorbidities & 0 & 0 & 1 \\
\hline
\end{tabular}

TABLE 2. DISTRIBUTION OF CLINICAL COMORBIDITIES BY ETIOLOGY IN ALL PATIENTS WITH CONGENITAL MICROCEPHALY ASSESSED FROM RECORDS OF THE INTEGRATED REHABILITATION CENTER, TERESINA (PI).

\begin{tabular}{l|l|l|l}
\multirow{2}{*}{ Clinical Variables } & \multicolumn{2}{|l|}{ Microcephaly Etiology } & $\mathrm{p}$ \\
\cline { 2 - 4 } & Zika (38) & Não-Zika (29) & \\
\hline Epilepsy & $30(78.9 \%)$ & $17(58.6 \%)$ & 0.106 \\
\hline Irritability & $20(52.6 \%)$ & $17(58.6 \%)$ & 0.805 \\
\hline Dysphagia & $16(42.1 \%)$ & $6(20.7 \%)$ & 0.073 \\
\hline Musculoskeletal Comorbidities & $7(18.4 \%)$ & $6(20.7 \%)$ & 1 \\
\hline Cardiovascular Comorbidities & $1(2.6 \%)$ & $2(6.9 \%)$ & 0.574 \\
\hline Endocrine Comorbidities & 0 & 0 & 1 \\
\hline
\end{tabular}


diversity of systemic changes emphasized the need for multidisciplinary care ${ }^{6}$.

Compared with clinical characterization studies of patients with microcephaly that described cognitive and intellectual alterations, the nondescription of cognitive impairment in our sample was a limitation, justified by the mean age of the patients. However, all the children analyzed presented neuropsychomotor development delay (such as social smile, head support, the age for sitting up, following family members, and eye contact).

Other more recent studies have identified and quantified common neurological outcomes in children with evidence of congenital infection by ZIKV. In one of them, Moura da Silva et al. ${ }^{7}$, in a sample of 48 children with probable infection by ZIKV, based on protocols from the Ministry of Health, identified that $86.7 \%$ presented microcephaly, with more than half of them presenting severe microcephaly. Of all children, 85.4\% had irritability, the most common symptom described, followed by pyramidal and extrapyramidal symptoms (56.3\%), epileptic seizures (50.0\%), and dysphagia (14.6\%) ${ }^{7}$. As for the series by Alves et al. ${ }^{8}$, which included 106 children with congenital ZIKV syndrome, $37.7 \%$ of the children had epileptic seizures in the observation period, with a median of 192-day crisis occurrence until the first report, from the date of birth. $43.3 \%$ of the seizures were characterized as spasms, $22.7 \%$ generalized tonic attacks, $20.5 \%$ were partial, and $4.5 \%$ were other types of seizures.

In fact, in this sample, irritability and epilepsy were found in more than $50 \%$ of children with microcephaly by ZIKV. We did not aim to explore all possible pyramidal and extrapyramidal motor neurological disorders in our study, so that the prevalence of musculoskeletal disorders was significantly lower (18.4\%).

Our results did not show any statistically significant differences when comparing the frequency of demographic and clinical variables between the groups of children with ZIKV microcephaly and those with non-ZIKV microcephaly. This indicates that, in patients with microcephaly, the mere presence of variables such as epilepsy or dysphagia should not serve as an indicator that suggests the diagnosis of ZIKV infection. However, it is possible that in larger samples, the same analysis confirms the significance of the differences between the groups in relation to such comorbidities.

Regarding the possible greater occurrence of dysphagia in the female gender, both when analyzing all causes of microcephaly and when analyzing only the ZIKV subgroup, no studies were found evidencing such correlation. Indeed, this data is not easily found in the literature of series of congenital microcephaly cases, which generally only exposes percentages of individual characteristics of the sample, such as the frequency of children with dysphagia and frequency of male children, rather than frequency of male children with dysphagia.

Regarding cardiac comorbidities, Orofino et al. ${ }^{9}$ reported echocardiographic alterations in 120 children with intrauterine exposure to ZIKV. Of the total, $40 \%$ had cardiac defects noted on echocardiography, most of which were physiological changes or minor defects of little clinical relevance, in most cases patent foramen ovale (72.8\%). Only 13 children (10.8\%) had major cardiac defects, such as ventricular septal defect. Although at a much higher frequency than in the general population, in none of them was the defect severe enough to require immediate treatment in the first few days or months of life. Therefore, the author suggested that the guideline for the performance of echocardiography in patients with ZIKV syndrome should be the same as in the general population.

In our study, only one child with ZIKV microcephaly had cardiac abnormalities, a much lower frequency than in the study by Orofino et al. ${ }^{9}$. However, this data suggests that the importance given to the research of cardiac comorbidities in patients with ZIKV should be lower than other comorbidities, such as neurological ones.

The aspects of the microcephaly epidemic in the state of Piauí during the years 2015-2016 have been analyzed. During the pre-epidemic period (January to August 2015), the mean monthly incidence rate of congenital microcephaly was about 0.18 cases / 1000 live births, reaching, at the epidemic peak in November, 6.33 cases / 1000 live births (an increase of more than 35 times). Teresina, the state capital, faces serious problems of sanitation, infrastructure, waste management, and vector control, which helps explain the fact that it has concentrated around $44 \%$ of the cases of congenital microcephaly in the state. Moreover, in the semi-arid country area, precarious water reserve systems may have contributed to the proliferation of vector mosquitoes ${ }^{3}$.

A limitation of our study is the lack of a normocephalic control group, which makes it difficult to interpret the results of some variables, such as irritability. Another limitation is the high probability of selection 
bias since children with more severe illnesses are those typically found in a rehabilitation center.

\section{CONCLUSIONS}

The cases of microcephaly presented a discrete numerical difference in relation to gender. In addition, epilepsy, irritability, and dysphagia are the most frequent clinical findings in these patients, whereas abnormal cardiac manifestations account for less than
$5 \%$ of the cases. More than half of the patients with microcephaly presented ZIKV as a probable etiology, and in those cases, there was a higher prevalence, mainly of epilepsy and dysphagia, compared to other microcephaly etiologies.

The diversity of manifestations found in the clinical profile of patients with microcephaly emphasizes the need for an interdisciplinary approach to minimize the impact of the various comorbidities on the quality of life and development of the child.

\section{RESUMO}

OBJETIVO: Pretende-se, neste estudo, identificar a prevalência de variáveis clínicas em crianças com microcefalia.

MÉTODOS: Trata-se de um estudo transversal e observacional com dados coletados de prontuários de pacientes admitidos no ambulatório de microcefalia de um centro de referência em Teresina (PI). Foram coletados dados demográficos (gênero e idade) e clínicos (presença de epilepsia, disfagia, irritabilidade e comorbidades associadas). A frequência de Zika vírus como provável etiologia foi determinada a partir de padrões da tomografia computadorizada e da exclusão de outras etiologias por exames sorológicos.

RESULTADOS: Foram avaliados 67 prontuários de pacientes, sendo 31 do sexo masculino e 36 do sexo feminino, com idade média de 1 ano e 10 meses. As variáveis clínicas mais prevalentes foram epilepsia, presente em 47 das crianças (70,2\%), e irritabilidade, em 37 (55,2\%). Também com elevada frequência, 22 possuíam quadro de disfagia $(32,8 \%)$ e 13 apresentavam comorbidades osteomusculares (19,4\%). Apenas três pacientes da amostra tinham quadro de alterações cardiológicas (4,5\%) e nenhuma comorbidade endocrinológica foi encontrada. Trinta e oito crianças da amostra (56,7\%) apresentaram ZIKV como provável etiologia e, nesses casos, houve maior frequência de epilepsia e disfagia em comparação com outras etiologias, embora não de forma significativa estatisticamente.

CONCLUSÕES: Epilepsia, irritabilidade, disfagia e comorbidades osteomusculares foram as variáveis clínicas mais frequentes em crianças com microcefalia. Houve uma prevalência alta de síndrome de microcefalia congênita por ZIKV nessa amostra.

PALAVRAS-CHAVE: Microcefalia. Zika vírus. Epilepsia. Transtornos da deglutição.

\section{REFERENCES}

1. Harris SR. Measuring head circumference: update on infant microcephaly. Can Fam Physician. 2015;61(8):680-4.

2. Hanzlik E, Gigante J. Microcephaly. Children (Basel). 2017;4(6). Pii: E47.

3. Almeida IMLM, Ramos CV, Rodrigues DC, Sousa AC, Nascimento MLCAPCD, Silva MVBD, et al. Clinical and epidemiological aspects of microcephaly in the state of Piauí, Northeastern Brasil, 2015-2016. J Pediatr (Rio J). 2018;pii: S0021-7557(18)30129-3.

4. Brasil. Ministério da Saúde. Orientações integradas de vigilância e atenção à saúde no âmbito da Emergência de Saúde Pública de Importância Nacional. Brasília: Ministério da Saúde;2017.

5. Watemberg N, Silver S, Harel S, Lerman-Sagie T. Significance of microcephaly among children with developmental disabilities. J Child Neurol. 2002;17(2):117-22.
6. von der Hagen M, Pivarcsi M, Liebe J, von Bernuth $\mathrm{H}$, Didonato N, Hennermann JB, et al. Diagnostic approach to microcephaly in childhood: a two-center study and review of the literature. Dev Med Child Neurol. 2014;56(8):732-41.

7. Moura da Silva AA, Ganz JS, Sousa PD, Doriqui MJ, Ribeiro MR, Branco $M D$, et al. Early growth and neurologic outcomes of infants with probable congenital Zika virus syndrome. Emerg Infect Dis. 2016;22(11):1953-6.

8. Alves LV, Cruz DCS, van der Linden AMC, Falbo AR, Mello MJG, Paredes $C E$, et al. Epileptic seizures in children with congenital Zika virus syndrome. Rev Bras Saúde Mater Infant. 2016;16(supl. 1):S27-31.

9. Orofino DHG, Passos SRL, Oliveira RVC, Farias CVB, Leite MFMP, Pone $\mathrm{SM}$, et al. Cardiac findings in infants with in utero exposure to Zika virus: a cross sectional study. PLoS Negl Trop Dis. 2018;12(3):e0006362. 